\title{
LEVELS OF COMPATIBILITY IN BRASSICA OLERACEA
}

\author{
L. E. WATTS \\ Crop Research Division, Department of Scientific and Industrial Research, \\ Lincoln, Christchurch, New Zealand
}

\section{InTRODUGTION}

Received 8.v.67

THE presence of a self-incompatibility system in Brassica oleracea $\mathrm{L}$. has been established by several investigators (e.g. Kakizaki, 1930; Nelson, 1927; Stout, 1938) and its sporophytic nature confirmed (e.g. Bateman, 1955; Sampson, 1957). Thompson and Taylor (1965) used plants of marrowstem kale which were homozygous for specific $S$ alleles to show the presence of similar $S$ alleles in the related botanical varieties dwarf curled kale, purple sprouting broccoli, savoy cabbage and wild cabbage. Their investigations suggested that the horticultural forms of $B$. oleracea have a restricted range

TABLE 1

Compatibility relationships in botanical varieties of $\mathrm{B}$. oleracea

\begin{tabular}{|c|c|c|}
\hline $\begin{array}{l}\text { Level of } \\
\text { self-incompatibility }\end{array}$ & Variety & Reference \\
\hline High & $\begin{array}{l}\text { Kale } \\
\text { Round-head cabbage }\end{array}$ & $\begin{array}{l}\text { Thompson, } 1965 \\
\text { Nelson, 1927; Odland and Noll, } 1950\end{array}$ \\
\hline High to moderate & $\begin{array}{l}\text { Round-head cabbage } \\
\text { Savoy cabbage } \\
\text { Green sprouting broccoli }\end{array}$ & $\begin{array}{l}\text { Adamson, 1965 } \\
\text { Nelson, 1927; Thompson and Taylor, } \\
\text { 1965 } \\
\text { Anstey, 1954; Sampson, 1957; Martin, } \\
\text { 1962 }\end{array}$ \\
\hline Moderate & $\begin{array}{l}\text { Autumn and winter cauli- } \\
\text { flower }\end{array}$ & Watts, 1963,1965 \\
\hline Moderate to low & $\begin{array}{l}\text { White sprouting broccoli } \\
\text { Brussels sprout }\end{array}$ & $\begin{array}{l}\text { Nelson, } 1927 \\
\text { Johnson, 1955; Thompson and Taylor, } \\
1965\end{array}$ \\
\hline Low & $\begin{array}{l}\text { Green kohlrabi } \\
\text { Purple sprouting broccoli }\end{array}$ & $\begin{array}{l}\text { Nelson, } 1927 \\
\text { Nelson, 1927; Thompson and Taylor, } \\
\quad 1965\end{array}$ \\
\hline Very low & Early summer cauliflower & Watts, 1963, 1965 \\
\hline
\end{tabular}

of $S$ alleles which are low in the dominance series compared with those in marrow-stem kale-a situation which may be attributable to more rigid selection within the horticultural than the agricultural types. The selfincompatibility reactions of $B$. oleracea (table 1 ) have been examined in various ways: studies of stigma colouration after pollination, identifications of $S$ alleles, seed-set per pod (often converted into arbitrary classes for genetic interpretation), an index of mass to self-pollinated seed-set and the percentage selfs in a single plant progeny after open-pollination.

Most cultivars within $B$. oleracea have been produced by mass selection and pollination so that differences in the compatibility levels probably 
indicate past selection intensities. Modern breeding techniques, however, often require the production of inbred lines for use alone, in groups for the production of synthetic varieties, or in pairs, for the production of $F_{1}$ hybrids. Thus, a knowledge of the self-incompatibility level within a cultivar is basic to the formulation of a breeding programme and may also be informative on the relative merits of past selection techniques.

The present paper studies the compatibilities shown by plants and cultivars within $B$. oleracea as an aid to the formulation of breeding programmes.

\section{Materials AND methods}

Seeds of 19 cultivars of all botanical varieties of Brassica oleracea except cauliflower were sown in six-inch pots. Apart from ensuring that plants were true to type no selection was practised in this experiment and no assessment of quality or morphology was made. Plants overwintered in the open so that flower initiation could take place after receiving a cold stimulus. Single inflorescences were produced on each plant in the spring and part of each was covered by an insect-proof glassine bag while the other part remained uncovered to allow insect-pollination. No less than 12 plants were flowering at any one time and insects were continually active through the flowering season. Part-inflorescences protected by bags were continually agitated by the wind and good dispersal of self-pollen occurred. It has been shown (Nelson, 1927; Watts, 1963) that the seed-set by this form of selfpollination is almost as good as that resulting from self-pollination by brush, and by this method it is possible to study a large number of plants. In order to assess the compatibility level of each plant, 10 selfed and 10 masspollinated pods were taken at random and their seeds counted. To assess the seed-bearing potential, ovule numbers were also counted in five of the pods.

\section{RESPONSES TO SELF- AND MASS-POLliNATION}

\section{Ovule and seed counts}

In general, studies of sporophytic self-incompatibility describe the consequences of a reaction between pollen and stigma, i.e. an all or nothing effect, although small quantities of selfed or crossed seed may be set and the collective reactions are then described as pseudocompatibility. Interpretations may be complicated by differences in fertility per se but these are taken into account in table 2 by comparing both self- and mass-seed-set as percentages of the ovule number for the appropriate variety. The numbers of plants in particular compatibility grades are shown in table 3.

\section{Self-incompatibility}

From table 2 it is apparent that an appreciable degree of self-incompatibility exists within all botanical varieties of $B$. olerace $a$ studied although there is marked variation in self-incompatibility at the varietal level. The most intense incompatibility reaction was found in the sprouting broccoli and the cabbage group, but although similar in mean value the latter was not composed of such uniform varietal responses. The most self-compatible group was the Brussels sprout, giving twice as much selfed-seed as sprouting broccoli and cabbage. 
In spite of the generally low levels of self-compatibility, table 3 indicates that small numbers of plants with fairly high self-compatibility may be found in most cultivars and botanical varieties. The Brussels sprout cultivar Earlipick showed 2 plants out of 10 and cultivar Fillbasket 1 plant out of 19

TABLE 2

Mean seed-set by self- and mass-pollination expressed as a percentage of the mean ovule number

$\begin{array}{cccc}\text { Bot. var+cultivar } & \begin{array}{c}\text { Selfed } \\ \text { seed-set }\end{array} & \begin{array}{c}\text { Massed } \\ \text { seed-set }\end{array} & \begin{array}{c}\text { Mean } \\ \text { ovule No. }\end{array}\end{array}$

Brussels sprout

Camb. No. 5

Earlipick

Fillbasket

Long Island

Wintercrop

Mean

\section{Cabbage}

Best of All

Ferry's Round Dutch

Glory of Enkhuizen

Golden Acre

Greenback

Greyhound

Ormskirk Med. Savoy

Mean

Mean (excl. last 2)

Kale

Giant Stem (in field)

Giant Stem (in pots)

Dwarf Curled

\section{Kohl rabi}

Green
Purple Vienna

Mean

Sprouting broccoli

De Cicco

Green Mountain

Morse's Med. Late

Mean

$\begin{array}{lll}10 \cdot 6 \pm 2 \cdot 5 & 60 \cdot 6 \pm 5 \cdot 1 & 23 \cdot 9 \pm 0 \cdot 5 \\ 40 \cdot 5 \pm 9 \cdot 1 & 69 \cdot 7 \pm 4 \cdot 3 & 19 \cdot 1 \pm 1 \cdot 5 \\ 22 \cdot 1 \pm 4 \cdot 0 & 63 \cdot 6 \pm 3 \cdot 1 & 24 \cdot 4 \pm 0 \cdot 6 \\ 22 \cdot 4 \pm 3 \cdot 0 & 61 \cdot 1 \pm 3 \cdot 9 & 20 \cdot 4 \pm 1 \cdot 0 \\ 22 \cdot 2 \pm 8 \cdot 0 & 66 \cdot 8 \pm 6 \cdot 0 & 24 \cdot 1 \pm 1 \cdot 5 \\ 23 \cdot 6 \pm 6 \cdot 0 & 64 \cdot 4 \pm 4 \cdot 6 & 22 \cdot 4 \pm 1 \cdot 2\end{array}$

$17 \cdot 0 \pm 5 \cdot 2$

$6 \cdot 8 \pm 3 \cdot 4$

$15 \cdot 4 \pm 3 \cdot 6$

$5 \cdot 4 \pm 1 \cdot 6$

$3 \cdot 1+1 \cdot 5$

$21 \cdot 6 \pm 1 \cdot 0$

$0 \cdot 0 \pm 0 \cdot 0$

$9 \cdot 9 \pm 3 \cdot 1$

$9 \cdot 5 \pm 3 \cdot 4$

$56 \cdot 1 \pm 10 \cdot 9$
$43 \cdot 2 \pm 10 \cdot 0$
$65 \cdot 8 \pm 4 \cdot 3$
$17 \cdot 8 \pm 3 \cdot 3$
$67 \cdot 3 \pm 4 \cdot 4$
$56 \cdot 8 \pm 0 \cdot 0$
$70 \cdot 3 \pm 0 \cdot 0$
$53 \cdot 9 \pm 6 \cdot 2$
$50 \cdot 6 \pm 7 \cdot 3$

$26 \cdot 7 \pm 0 \cdot 7$

$23 \cdot 5 \pm 0 \cdot 9$

$27 \cdot 8+0 \cdot 7$

$23 \cdot 6 \pm 0 \cdot 7$

$23 \cdot 6 \pm 0 \cdot 6$

$30 \cdot 9 \pm 2 \cdot 0$

$32 \cdot 9 \pm 1 \cdot 1$

$27 \cdot 0 \pm 1 \cdot 1$

$25 \cdot 0 \pm 0 \cdot 7$

$\begin{array}{ll}11 \cdot 4 \pm 2 \cdot 2 & 68 \cdot 3 \pm 3 \cdot 2 \\ & 50 \cdot 3 \pm 5 \cdot 7 \\ 20 \cdot 1 \pm 4 \cdot 1 & 59 \cdot 9 \pm 6 \cdot 5\end{array}$

$39 \cdot 3 \pm 0 \cdot 8$

$33 \cdot 6 \pm 0 \cdot 9$

$25 \cdot 8 \pm 1 \cdot 0$

$12 \cdot 4 \pm 3 \cdot 1$

$18 \cdot 4 \pm 2 \cdot 9$

$48 \cdot 6 \pm 4 \cdot 3$

$25 \cdot 8 \pm 1 \cdot 0$

$59 \cdot 9 \pm 0.8$

$25 \cdot 4 \pm 1 \cdot 6$

$15 \cdot 4 \pm 3 \cdot 0$

$54 \cdot 3 \pm 3 \cdot 0$

$25 \cdot 6 \pm 1 \cdot 3$
$35 \cdot 2+5 \cdot 8$

$48.8 \pm 5.9$

$40 \cdot 0 \pm 2 \cdot 7$

$41 \cdot 3 \pm 5 \cdot 0$
$24 \cdot 7+2 \cdot 9$

$28 \cdot 4 \pm 0 \cdot 0$

$20 \cdot 5 \pm 0 \cdot 5$

$24 \cdot 5 \pm 1 \cdot 7$

with almost complete self-compatibility. The significance of table 3 lies not so much in the mean of compatibility grades but in the small percentage of plants lying well away from the mean-such as the 6 per cent. of giantstem kale and the one plant of green kohl rabi-and depends upon the extent to which the differences between plants are genetic. It seems probable that past selection pressures have produced slightly different compatibility responses within cultivars and the breeding system may be further affected by selection of plants from one or other end of the compatibility grades. 


\section{Ovule fertility}

Although mean ovule numbers for botanical varieties were very similar (range 22 to 27), varietal differences were quite marked in sprouting broccoli (20-28) and cabbage (24-33). Further, giant kale grown in the field had

TABLE 3

Self-compatibility of botanical varieties of B. oleracea $L$., with selfed-seed-set expressed as a percentage of mean ovule number per variety

No. of plants within compatibility grade (10 per cent. intervals)

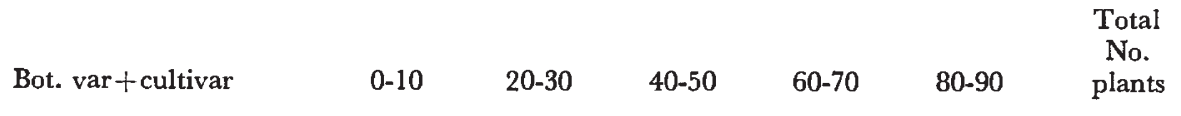

Brussels sprout

Camb No. 5

Earlipick

Fillbasket

Long Island

Wintercrop

Total

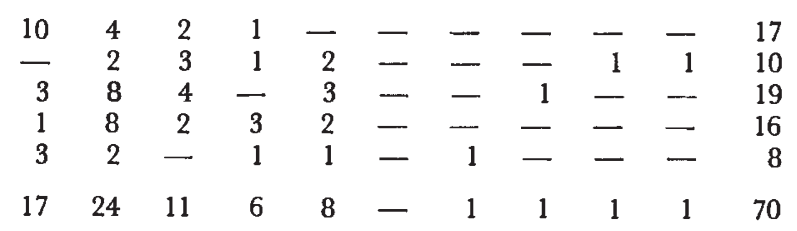

Cabbage

Best of All

Ferry's Round Dutch

Glory of Enkhuizen

Golden Acre

Greenback

Greyhound

Ormskirk Med. Savoy

Total

Kale

Giant Stem (in field)

Giant Stem (in pots)

Dwarf Curled

$$
\begin{array}{rrrrrrrrrrr}
5 & 1 & - & 2 & 1 & - & - & - & - & - & 9 \\
8 & - & - & 1 & - & - & - & - & - & - & 9 \\
8 & 2 & 4 & 1 & 1 & - & - & - & - & - & 16 \\
12 & 4 & - & - & - & - & - & - & - & - & 16 \\
10 & 2 & - & - & - & - & - & - & - & - & 12 \\
-1 & - & 2 & - & - & - & - & - & - & - & 2 \\
44 & 9 & 6 & 4 & 2 & - & - & - & - & - & 65
\end{array}
$$

Kohl rabi

Green

Purple Vienna

Total

$$
\begin{array}{lllllllllll}
21 & 8 & 3 & 1 & - & 2 & - & - & - & - & 35 \\
\text { Not recorded } & & & & & & & & & & \\
1 & 3 & 2 & 2 & - & - & - & - & - & - & 8
\end{array}
$$

Sprouting broccoli

De Cicco

Green Mountain

Morse's Med. Late

Total

$\begin{array}{rrrrrrrrrr}10 & 6 & 2 & - & - & 1 & - & - & - & -19 \\ 5 & 4 & 2 & 4 & - & - & - & - & - & - \\ 15 & 10 & 4 & 4 & - & 1 & - & - & - & -\end{array}$

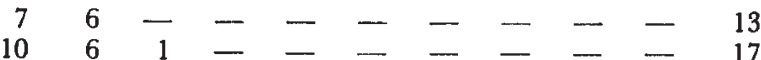

$$
\begin{aligned}
& \begin{array}{llll}
12 & 3 & 1 & -
\end{array}--17 \\
& \begin{array}{lllllllllll}
29 & 15 & 2 & 1 & - & - & - & - & - &
\end{array}
\end{aligned}
$$

a mean ovule number of 39 while those in pots had a mean of 34 . Both sets of giant kale differed markedly from the horticul tural kale " Dwarf curled ", which bore 26 ovules. Table 2 indicates that the potential for the development of ovules to seeds was not realised in any of the cultivars even under conditions of open pollination. Since many plants of all botanical varieties 
were flowering simultaneously and insects were continually present, it is very unlikely that low massed-seed-sets would be caused by poor or crossincompatible pollinations. It appears, however, that 100 per cent. compatibility is never realised, even when nutrients, pollinators or other factors are not limiting, as with giant-stem kale grown in the field, and a seed-set of 70 per cent. probably represents complete fertility.

The Brussels sprouts showed a consistently high percentage of massedseed-set, but cultivars within other groups were variable, Golden Acre cabbage and the sprouting broccoli having particularly low seed-sets.

An analysis was made between the figures for selfed and massed-seed-sets to investigate any correlation between them which would suggest developmental as well as genetic effects. No significant correlation, either linear or non-linear, was evident, however ( $r=0.376$ for 18 d.f. $)$.

\section{Discussion}

The range of distinct plant types and cultivars in Brassica oleracea is evidence of the effect of artificial selection over many years. Except in the agricultural kales and possibly kohl-rabi, selection for uniformity would be stringent although the intensity is limited by the need to produce sufficient seed.

Although marked changes of phenotype could be produced in a population or cultivar, the self-incompatibility mechanism would tend to impose its own restrictions upon changes in the general level of self-compatibility. Changes resulting from too limited a choice of parental plants would probably be avoided because of the accompanying inbreeding depression. Thus it seems likely that the effect and composition of the self-incompatibility system would remain similar over a wide range of cultivars. Thompson and Taylor (1965) noted that more intense selection had probably reduced the numbers of $S$ alleles in the horticultural cultivars, compared with those in marrow-stem kale. They ascribed the higher level of self-compatibility in the horticultural types to a bias which was introduced in favour of selfcompatible $S$ alleles by restricting selection to small numbers of plants.

Although there was no attempt to identify $S$ alleles in the present investigation, it was shown in table 3 that the self-incompatibility of marrowstem kale (60 per cent. plants showing almost complete self-incompatibility) was matched by that of cabbage and sprouting broccoli (68 and 62 per cent. respectively) which have probably been selected more rigorously. Brussels sprouts, however, which have probably undergone the same form of selection as the other horticultural types showed only 24 per cent. plants with complete self-incompatibility. In general these results confirm those of other investigators, although a few self-compatible plants have been found in sprouting broccoli (Anstey, 1954; Anstey and Moore, 1954) and cabbage (Adamson, 1965). It is conceivable that within these two botanical varieties self-compatibility is associated with a disadvantage such as inbreeding depression which operates against selection. Some evidence for this is available. Anstey (1954) found a 10 per cent. yield reduction in sprouting broccoli after inbreeding for two to four generations, while Myers and Fisher (1944) and Odland and Noll (1950) recorded marked inbreeding depression in cabbage following inbreeding. By contrast, Johnson (1955) found that inbred lines from Brussels sprout plants showing some self-compatibility were quite uniform and showed little loss of vigour, while Watts (1965) and 
Chatterjee and Mukherjee (1965) showed that it was possible even to obtain increased yield of early summer cauliflower by inbreeding.

Johnson (1955) studied the self-incompatibility system in Brussels sprouts and concluded that determination ". . . is made more difficult by the widespread occurrence of self-fertility". In the variety Cambridge 3 he found 8 plants out of 39 to be completely self-compatible (20.5 per cent. compared with the mean for 5 varieties of 23.6 per cent. in the present study), 14 of the remainder each produced 50 or more seeds per 100 flowers selfed and one produced 1200 seeds-approaching complete self-fertility. There appears to be no a priori reason why cabbage and sprouting broccoli should not ultimately move further towards self-compatibility without inbreeding depression, in line with Brussels sprouts and cauliflower (Adamson (1965) found greater self-compatibility in cultivar Golden Acre, although our studies do not support this).

The severity with which selection was practised has probably been directly responsible for differences in ovule fertility as shown in table 2. In general, sprouting broccoli had lowest ovule fertility while cabbage cultivar Golden Acre was the lowest of all varieties examined. According to Lerner (1954), "The deterioration of populations subjected to continued consanguineous mating represents a generally known phenomenon . . . and is largely found in traits connected with fitness". It is pointed out that the closer the relationship between a character and fitness the greater likelihood there is that the character will suffer inbreeding depression. Thus, the low level of ovule fertility in sprouting broccoli and Golden Acre cabbage may be a direct expression of a loss in fitness brought about by a high intensity of selection.

The effect of selection in the cauliflowers (Watts, 1963) has been to increase the level of self-compatibility, unlike the sprouting broccoli and cabbage, but the effect on fitness (as ovule fertility) is the same. Watts (unpublished) studied 98 plants of cauliflower, comprising 22 varieties, and found ovule fertility of 36.7 per cent. compared with 41.7 per cent. for the sprouting broccoli. In cauliflower, however, there are three distinct types based on maturity and also to some extent on self-compatibility, the early summer cauliflowers (being highly self-compatible) forming a separate compatibility group from the autumn and winter types. The ovule fertility of the early summer cauliflowers was 29.3 per cent. and of the other types 40.5 per cent. Thus it appears that in a normally out-crossed species such as Brassica oleracea the outcome of rigid selection may or may not be a higher level of self-compatibility, but some reduction of fitness, particularly fecundity, is inevitable.

\section{Summary}

1. The relative levels of compatibility of Brussels sprout, cabbage, curly kale, giant marrow-stem kale, kohl-rabi and sprouting broccoli were assessed by pollination of 19 cultivars.

2. Within-plant comparisons of fertility were made possible by selfpollinating open flowers on one part of each inflorescence and mass-pollinating those of the other part.

3. Although selection within horticultural types tends to be more stringent than for the agricultural types, thus favouring self-compatibility, cabbage and sprouting broccoli are as self-incompatible as agricultural kale. 
Brussels sprout showed the greatest self-compatibility while curly kale and kohl-rabi were intermediate.

4. The approach to greater self-compatibility in cabbage and sprouting broccoli may be restricted when a disadvantage such as inbreeding depression, operates against selection.

5. In all cultivars, seed-set from mass-pollination was not more than 74 per cent. of the potential (number of ovules), but in the sprouting broccoli group and one cabbage variety, fecundity was only 42 per cent. and 18 per cent. respectively. Such low levels were regarded as a deterioration in fitness due to inbreeding.

Acknowledgments.-I should like to thank Miss L. A. King and Miss E. Stevenson for their help in collecting and analysing the data.

\section{REFERENCES}

ADAMSON, R. M. 1965. Self- and cross-incompatibility in early round-headed cabbage. Can. 7. Plant Sci., 45, 493-498.

ANSTEY, T, H. 1954. Self incompatibility in green sprouting broccoli B. oleracea L. var italica Plenck. I. Its occurrence and possible use in a breeding programme. Canad. $\mathcal{F}$. agric. Sci., 34, 59-64.

Bateman, A. J. 1955. Self-incompatibility systems in angiosperms. III. Cruciferae. Heredity, 9, 53-68.

CHATTERJEe, s. s., AND MUKhERJEe, s. K. 1965. Selection and maintenance of cauliflower (Brassica oleracea L. var. botrytis L.). Ind. 7. Hortic., 22, 60-68.

Johnson, A. G. 1955. Ann. Rep. Nat. Veg. Res. Sta. for 1955, p. 14.

KAKIZAKI, Y. 1930. Studies on the genetics and physiology of self and cross-incompatibility in the Common Cabbage (Brassica oleracea L. var. capitata L.). 7ap. F. Bot., 5, 133-208. LERNER, 1. M. I954. Genetic Homoeostasis. J. Wiley and Sons, New York.

MARTIN, F. W. 1962. Factors affecting seed-set in cross-pollinations of green sprouting broccoli (Brassica oleracea L. var. italica Plenck). Euphytica, 11, 81-86.

MOORE, J. F., AND ANSTEY, T. H. 1954. A study of the degree of natural selfing in Green Sprouting Broccoli (B. oleracea L, var. italica). Proc. Amer. Soc. Hort. Sci., 63, 440-442. MYERS, C. H., AND FISHER, w. 1. 1944. Experimental methods in cabbage breeding and seed production. Mem. 259. Cornell Univ. A.E.S.

Nelson, A. 1927. Fertility in the Genus Brassica. 7. Genet., 18, 109-136.

ODLAND, M. L., AND NOLL, G. J. 1950. The utilization of cross-compatibility and selfincompatibility in the production of $\mathrm{F}_{1}$ hybrid cabbage. Proc. Amer. Soc. Hort. Sci., 55, 39 I-402.

SAMPSON, D. R. 1957. The genetics of self- and cross-incompatibility in Brassica oleracea. Genetics, 42, 253-263.

stout, A. B. 1938. The genetics of incompatibilities in homomorphic flowering plants. Bot. Rev., 4, 275-369.

тHOMPSON, K. F. 1957. Self-incompatibility in marrow-stem kale. I. Demonstration of a sporophytic system. 7. Genet., 55, 45-60.

THOMPSON, K. F., AND TAYLOR, J. P. 1965. Identical $S$ alleles in different botanical varieties of Brassica oleracea. Nature, 208, 306-307.

WATTS, L. E. 1963. Investigations into the breeding system of cauliflower Brassica oleracea var. botrytis (L.). I. Studies of self-incompatibility. Euphytica, 12, 323-340.

WATTS, L. E. 1965. Investigations into the breeding system of cauliflower. II. Adaptation of the system to inbreeding. Euphytica, 14, 67-77. 